\section{Commentary: A question of degrees}

\author{
William J. Phillips, MD, and \\ Mariya Geube, MD, FASE
}

Mild degree of hypothermia has persisted over the years in the perioperative management of patients requiring cardiopulmonary bypass (CPB). This practice has been based on the circumstantial, although never proven, premise that hypothermia may exert a global organ-protective effect, particularly regarding the central nervous system (CNS). The physiologic basis of this theory and its extended applications even beyond the perioperative arena are very well outlined by Nielsen and colleagues. ${ }^{1}$ On the flip side, the adverse effects of hypothermia are considerable and include coagulation derangements, dysfunction of enzymatic systems, acidosis, a decrease in tissue oxygen delivery, an increase in blood viscosity, and a decrease in erythrocyte deformability.

In this issue, Bianco and colleagues ${ }^{2}$ present propensity score analysis of 3202 patients undergoing nonemergent cardiac surgery with CPB over a 7-year period. The matched cohorts were divided into a normothermic $\left(>35^{\circ} \mathrm{C}\right)$ and hypothermic $\left(32^{\circ} \mathrm{C}-35^{\circ} \mathrm{C}\right)$ group with temperature-management decisions based on surgeon preference and patient characteristics. The primary outcome was survival, and secondary outcomes were postoperative complications and readmission rate. Median CPB bladder temperature was $34.2^{\circ} \mathrm{C}$ in the hypothermic and $35.7^{\circ} \mathrm{C}$ in the normothermic group. The groups were well matched regarding age, cardiovascular history and function, comorbidities, laboratory profiles, and surgeon. The authors did not find a difference in early- $(2.6 \%$ vs $2.4 \% ; P=.8)$ or long-term survival $(82.6 \%$ vs $81.63 \% ; P=.81)$. There

\footnotetext{
From the Department of Cardiothoracic Anesthesiology, Cleveland Clinic Foundation, Cleveland, Ohio.

Disclosures: The authors reported no conflicts of interest.

The Journal policy requires editors and reviewers to disclose conflicts of interest and to decline handling or reviewing manuscripts for which they may have a conflict of interest. The editors and reviewers of this article have no conflicts of interest.

Received for publication June 14, 2021; revisions received June 14, 2021; accepted for publication June 18, 2021; available ahead of print July 7, 2021.

Address for reprints: Mariya Geube, MD, FASE, Department of Cardiothoracic Anesthesiology, Cleveland Clinic Foundation, 9500 Euclid Ave, J4-328, Cleveland, OH 44195 (E-mail: geubem@ccf.org).

JTCVS Open 2021;7:243-4

2666-2736

Copyright (c) 2021 The Author(s). Published by Elsevier Inc. on behalf of The American Association for Thoracic Surgery. This is an open access article under the CC BY-NC-ND license (http://creativecommons.org/licenses/by-nc-nd/4.0/). https://doi.org/10.1016/j.xjon.2021.06.012
}

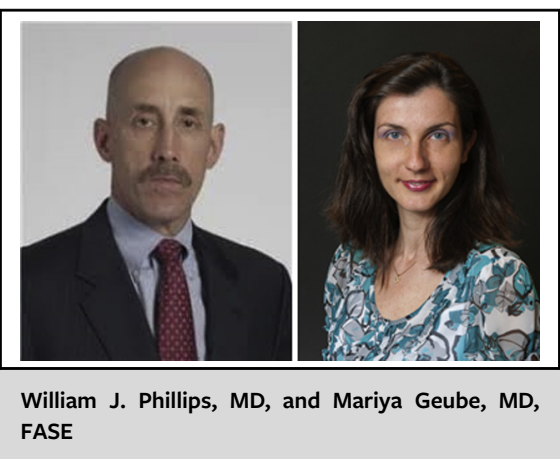

CENTRAL MESSAGE

A large, propensity-matched study did not demonstrate benefit of mild hypothermia over normothermia for routine cardiac surgery.

was a modest but statistically significant risk of acute renal failure (ARF) $(3.7 \%$ vs $2.4 \% ; P=.03)$ in the hypothermic group. There were no differences in outcomes related to transfusion requirements, use of intra-aortic balloon pump (IABP), infections, stroke, pneumonia, atrial fibrillation, hospital length of stay, and readmissions.

Myocardial protection during CPB is largely based on electromechanical arrest with hypothermia adding a potential supplemental benefit. ${ }^{3}$ The authors did not provide data on methods of myocardial protection, including temperature, composition, and delivery of cardioplegia solutions. Also, the only metric regarding post-CPB myocardial performance was IABP use; deployment of inotropic support, perioperative troponin trends, or echocardiographic performance data were not presented. It is therefore difficult to draw any conclusions regarding comparative myocardial protection in this setting, as IABP use is often a later intervention with a definite subjective component as to if/when it might be applicable. The implementation of hypothermia during CPB was affected by the individual surgeon's preference, and so was the transfusion practice. The authors did not find a difference in the transfusion requirements between the 2 groups; however, there is a lack of information regarding the transfusion protocols used, ie, use of antifibrinolytics, point-of-care coagulation monitoring, and transfusion triggers. For this reason, the results may not be linked solely to the temperature used during CPB but are likely a reflection of the individual transfusion practice. 
Concerning the effect of temperature on CNS, this study was not designed to elucidate milder degrees of cognitive impairment. Although the incidence of stroke was not different, peribypass acute CNS events are often embolic in nature and unrelated to global CNS protection strategies. In addition, target core temperatures were bladder temperatures; the adequacy of CNS cooling was not addressed, leaving open to question disparities in regional cooling and evidence of true CNS temperature differences. The study was also not designed to address rates of rewarming or perhaps most importantly, postbypass temperature "overshoot," both of which may be major contributors to CNS secondary insult.

ARF was modestly more prevalent in the hypothermia cohort (3.7 vs $2.4 \% ; P=.03$ ). These incidences of ARF requiring dialysis are consistent with historic figures. ${ }^{4} \mathrm{How}-$ ever, the study was not designed to suggest whether the ARF subgroups had longer CPB times, more valvular procedures, or more aortic vascular disease. The severity of perioperative anemia in the ARF cohort was also not evaluated, as a hematocrit $<24$, particularly in patients with obesity, may predispose to acute kidney injury. ${ }^{5}$ Also, as the kidneys may rewarm more rapidly than other tissues, rapid and/or excessive rewarming (rather than the depth of hypothermia) may predispose to acute kidney injury. ${ }^{6}$
The authors are to be well commended on a large, multiyear trial with a very meaningful follow-up period. Cohorts were well matched across a large number of clinically relevant parameters. Despite the potential of confounding and influence of selection bias related to the retrospective design, this study clearly adds weight to the body of literature calling into the question the benefits of deliberate hypothermia for routine cardiac surgery.

\section{References}

1. Nielsen N, Wetterslev J, Cronberg T, Erlinge D, Gasche Y, Hassager C, et al. Targeted temperature management at 33 degrees $\mathrm{C}$ versus 36 degrees $\mathrm{C}$ after cardiac arrest. N Engl J Med. 2013;369:2197-206.

2. Bianco V, Kilic A, Aranda-Michel E, Dunn-Lewis C, Serna-Gallegos D, Chen S, et al. Mild hypothermia versus normothermia in patients undergoing cardiac surgery. J Thorac Cardiovasc Surg Open. 2021;7:230-42.

3. Gaillard D, Bical O, Paumier D, Trivin F. A review of myocardial normothermia: its theoretical basis and the potential clinical benefits in cardiac surgery. Cardiovasc Surg. 2000;8:198-203.

4. Anderson RJ, O’Brien M, MaWhinney S, VillaNueva CB, Moritz TE, Sethi GK, et al. Renal failure predisposes patients to adverse outcome after coronary artery bypass surgery. VA Cooperative Study \# 5. Kidney Int. 1999;55:1057-62.

5. Ranucci M, Aloisio T, Carboni G, Ballotta A, Pistuddi V, Menicanti L, et al. Acute kidney injury and hemodilution during cardiopulmonary bypass: a changing scenario. Ann Thorac Surg. 2015;100:95-100.

6. Boodhwani M, Rubens FD, Wozny D, Nathan HJ. Effects of mild hypothermia and rewarming on renal function after coronary artery bypass grafting. Ann Thorac Surg. 2009;87:489-95. 